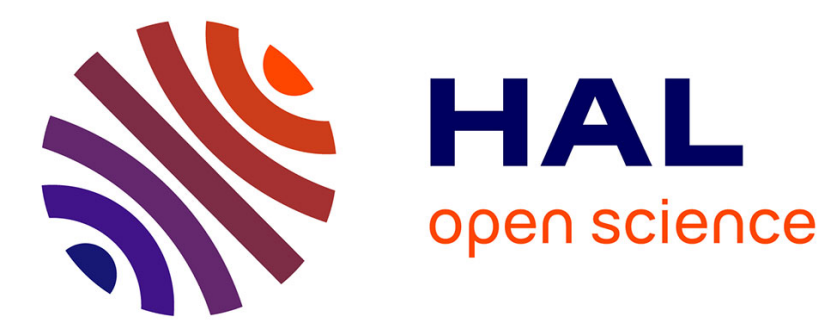

\title{
A Managed Bandwidth Reservation Protocol for Ad Hoc Networks
}

Claude Chaudet, Olivier Festor, Isabelle Guérin Lassous, Radu State

\section{To cite this version:}

Claude Chaudet, Olivier Festor, Isabelle Guérin Lassous, Radu State. A Managed Bandwidth Reservation Protocol for Ad Hoc Networks. [Research Report] RR-5013, INRIA. 2003, pp.10. inria-00071571

\section{HAL Id: inria-00071571 \\ https://hal.inria.fr/inria-00071571}

Submitted on 23 May 2006

HAL is a multi-disciplinary open access archive for the deposit and dissemination of scientific research documents, whether they are published or not. The documents may come from teaching and research institutions in France or abroad, or from public or private research centers.
L'archive ouverte pluridisciplinaire HAL, est destinée au dépôt et à la diffusion de documents scientifiques de niveau recherche, publiés ou non, émanant des établissements d'enseignement et de recherche français ou étrangers, des laboratoires publics ou privés. 
INSTITUT NATIONAL DE RECHERCHE EN INFORMATIQUE ET EN AUTOMATIQUE

\section{A Managed Bandwidth Reservation Protocol for Ad Hoc Networks}

Claude Chaudet, Olivier Festor, Isabelle Guérin Lassous, Radu State

\section{No 5013}

Novembre 2003

THÈME 1

\section{apport \\ de recherche}





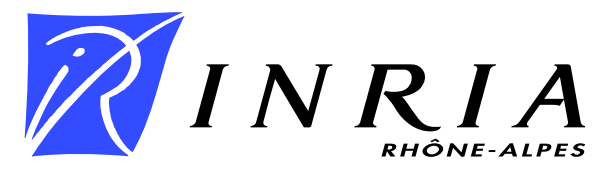

\title{
A Managed Bandwidth Reservation Protocol for Ad Hoc Networks *
}

\author{
Claude Chaudet, Olivier Festor, Isabelle Guérin Lassous, Radu State \\ Thème 1 - Réseaux et systèmes \\ Projets ARES et Madynes
}

Rapport de recherche no 5013 - Novembre 2003 - 10 pages

\begin{abstract}
In this paper we present a bandwidth reservation protocol called BRuIT designed to operate in mobile ad hoc networks. The protocol is provided together with a policy-based outsourcing model enabling context-aware reservation authorization.
\end{abstract}

Key-words: ad hoc networks, bandwidth management, network management, basedpolicy approach

* This work was done in the context of the RNRT project SAFARI. 


\section{Un protocole de réservation de bande passante dans les réseaux ad hoc couplé à une gestion à base de politiques}

Résumé : Cet article présente un protocle de réservation de bande passante, appelé BRuIT, pour les réseaux ad hoc couplé à une gestion de réseaux à base de politiques. Cette gestion permet d'accepter ou de refuser les réservations en fonction de l'état du réseau.

Mots-clés : réseaux ad hoc, gestion de bande passante, gestion de réseaux, approche à base de politiques 


\section{Introduction}

Mobile ad hoc networks are an evolution of wireless networks in which no fixed infrastructure is needed. Nodes communicate directly between each other, without the need for a base station. Most of the works in ad hoc networks have been dedicated to routing problems. The field of QoS providing is still widely open. But this issue is very challenging in ad hoc networks where the badwidth is scarce, the packet transmissions are more subject to errors and the network is highly dynamic.

In this paper, we present a bandwidth reservation framework for ad hoc networks that includes a reservation protocol that is strongly coupled to an authorization framework implemented within the management plane using a policy-based approach.

The paper is organized as follows. After a quick overview of QoS in the context of mobile ad hoc networks, Section 1 describes the reservation protocol. The management plane for this protocol together with its implementation is described in section 2. The paper concludes with a summary of the presented results together with the identification of some future work.

\section{BRuIT: a Bandwidth Reservation under InTerferences protocol for ad hoc networks}

In [17], Wu and Harms classify the QoS solutions in ad hoc networks into four categories: QoS models, Mac QoS protocols, signaling protocols and QoS routing protocols. QoS models consist in architectural concepts that define the QoS providing philosophy. Two actual solutions fit into this category: FQMM [18] and 2LQoS [10]. Mac QoS protocols can be seen as the tools that are used to effectively provide QoS. Many works have been made in this field, especially on how to provide mac-level priorities between mobiles and/or flows. Different works can be found in $[1,12,8,14]$. QoS signaling protocols define sets of control packets that are used to manage the network. These control packets can be used to convey information on the amount of resources available, to establish and maintain routes, to propagate topology, etc. Different signaling protocols are described in [7, 2, 13]. QoS routing is probably the most active of the QoS for ad-hoc networks sub-domains. Many directions are explored to enhance the discovery and maintenance of routes matching a particular criteria. In order to find these routes, the protocol should be able to perform admission control. This means that these protocols need accurate information on the network state and they need to share a common policy. Therefore, control information might need to be exchanged, adding to the cost of the route finding process. The works of $[4,16,9]$ propose such QoS routing protocols. In all the protocols previously mentioned, mobiles accept or reject traffic according to their local state, i.e. to their one hop neighborhood. Admission control is performed using information on the available bandwidth, the delay and/or the stability with one hop neighbors. None of these protocols consider the interferences phenomenon that can occur in radio networks. For instance, with the 802.11 standard, even if two transmitting mobiles are too far from each other to communicate, they may still have to share the bandwidth, due to radio signal propagation laws, making difficult the evaluation of the the bandwidth 


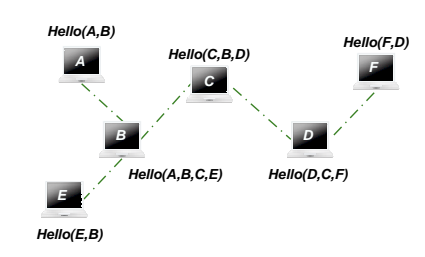

Figure 1: Propagation of information in the two hops neighborhood

available for the applications.

BRuIT has been designed with the aim of providing bandwidth reservation to the applications considering interferences influence. The first description of BRuIT has been given in [3]. This protocol consists basically in a reactive routing with quality of service based on each node's state.

BRuIT defines a signaling protocol to bring information to the mobiles on their neighborhood. The goal of these exchanges is to evaluate the amount of bandwidth used in a neighborhood larger than one hop in order to take into account the bandwidth wasted by interferences. Simulations and experiments we have carried out indicate that the interfering area is about two times larger than the communication area. Therefore, in BRuIT, each mobile evaluates its available bandwidth according to the used bandwidth in its two hops neighborhood. To maintain this knowledge, each mobile periodically emits a signaling packet containing information on its used bandwidth and its one hop neighbors', as shown in Figure 1. Thus, each mobile periodically gets the knowledge on the bandwidth used by its two hop neighbors and can then use this information for admission control.

The routing part of the protocol is reactive. The route research consists in the flooding of a route request with QoS requirements. When a mobile receives such a request, it performs an admission control based on the large knowledge previously described. If the admission control fails, the request is simply not forwarded. When the destination receives such a request, it also performs admission control and, if the control succeeds, replies with a route reply on the reverse path. Mobiles on the path receiving this route reply verify the availability of resources before forwarding the message. If this check fails, an error message is sent to the source that can then initiate a new route research, otherwise the mobile reserves the required bandwidth, as shown in Figure 2. When the route reply is received by the source, the communication can begin until there is no more data to transmit, or until the route no longer satisfies the negotiated criteria. If the communication ends normally, the source sends a message on the path to free the resources.

When a mobile on an active route moves, the quality of the route may be degraded or the route may even get disconnected. When a mobile cannot reach the next mobile on an active route anymore, it has to find a new route to the destination. Two alternatives are possible: it can try to repair the initial route by trying to join a mobile farther in the route or compute a new feasible route from the breaking point; the source or mobiles in the path may 


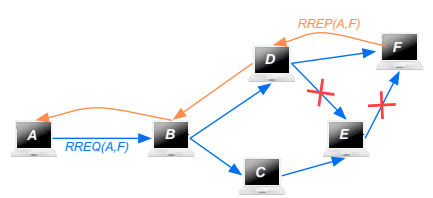

Figure 2: Route research and reservation process

also store alternative routes in case of link failure. If the route remains connected but the quality of service requirement is not satisfied anymore, the route shall also be recomputed. This situation can easily happen when a mobile transmitting some traffic moves so that it begins interfering with a previously accepted transmission. The two solutions proposed above can be applied but there may not exist any other routes between the source and the destination. Moreover, the route reconstruction is an expensive process. BRuIT proposes another alternative consisting in a degradation of the flows: when a mobile notes a quality degradation on one of its route, it shall downgrade its flows' bandwidth allocation levels. This process is iterated until a stable situation is reached.

This mechanism requires that applications specify, in addition of their desired rate, the minimal rate under which they can not operate and the amount of bandwidth that can be removed at each degradation step. A mobile that degrades its flows must inform the other mobiles on the route so that they take the corresponding measures. When the disruption has disappeared, the mobile may restore its flows by the same incremental steps until the initial rate is reached.

\section{A Policy Based Management framework for BRuIT}

To allow context-aware reservation decisions, they need to be performed in the management plane. To this end we extended the policy-based management framework defined within IETF to ad hoc environments and defined the usage of the Common Open Policy Service in the context of BRuIT. These extensions are described in this section.

\subsection{Policy-based management and ad hoc networks}

The policy based management approach for network emerged [6] as a scalable solution towards the management of large networks. It is based on pushing more intelligence in the network using a set of policies for its management. These policies are specified by a network manager, and installed on one or several locations called Policy Decision Points (PDP). Agents located on devices are responsible to connect to these PDPs and either retrieve their corresponding policies or outsource the decisions concerning policies to these entities. Policies are mapped to a device specific configuration and enforced on these devices by the agents (called Policy Enforcement Points: PEP). The communication between a PDP and a PEP has been standardized by the IETF under the Common Open Policy Service 
Protocol (COPS) specification [6]. This protocol offers a set of predefined primitives used to establish connections and manage them and provides the possibility to transport userdefined objects between a PEP and a PDP. In order to extend policy based management to ad-hoc infrastructures, several issues must be dealt with:

- PDP bootstrapping. A new node joining an ad-hoc network needs to know the address and identity of the PDP.

- Management traffic discrimination. Traffic used for management purpose should be differentiated with respect to ordinary data traffic.

- Moderate bandwidth overhead.

- Specific COPS extensions/adaptations support. The COPS protocol must be adapted with target deployment specific features.

Existing work on policy based management approaches for ad-hoc networks is relatively modest. An adaptation of the SNMP framework is described in [5], while a mobile agent management infrastructure is described in [15]. All these approaches rely on clustering within the management plane to reduce the management traffic while maintaining accurate state and connectivity among the management entities (manager/policy decision points and agents/policy enforcement points). The extension of policy based management for enterprise level ad-hoc infrastructures is addressed in [19], while clustering techniques for management interactions are considered in [11]. Our approach for extending policy based management architectures in ad-hoc network is based on integrating radio level information and ad-hoc routing protocols within the management plane. In this context, BRuIT is typically a good candidate to be considered as a foundation for the management infrastructure.

\subsection{The BRuIT management plane}

In line with the current approaches towards extending policy based management to ad-hoc topologies, we define a node architecture (see Figure 3) together with BRuIT specific objects for COPS. The software architecture is composed of several modules:

- a BRuIT communication module responsible with the BRuIT inter-node signaling.

- a self-configuration layer required to bootstrap the PDP within an ad-hoc network. The major functionality of this module is to determine the IP addresses of peer PDPs whenever a node joins an existing network in order to establish a management session.

The current bootstrapping strategy is relatively simple: as soon as a node joins an ad-hoc network, it obtains from each link level neighbor the known PDP addresses and the required estimated hop-count to them. The closest PDP is selected to connect to. This association can change over time: if a new PDP node joins the network and gets closer to an existing PEP, the latter can request to connect to this PDP. The self-configuration module is concerned basically with associating PEPs to PDPs such that localized grouping based on topological distances is possible. 
- A Policy Enforcement Point responsible to grant/deny connection establishment requests and path reservation requests. In fact, whenever a BRuIT message is received by the BRuIT module, it is forwarded to the PEP. The latter might request a decision from the PDP, or might directly decide how these requests should be treated.

Several interfaces between the modules are defined:

- The interface between the BRuIT module and the PEP comprises five exchanged message types:

1. Route request sent by a node to find a route towards another node. Parameters included in this message include the required bandwidth, source address, target address, receiving interface and last forwarding node.

2. Reservation request used to reserve a path traversing several nodes. Additional parameters in this message are related to target/source addresses, route identification, receiving interface, and the next hop.

3. Neighborhood messages containing radio level link state information about the neighborhood of a node.

4. Route state messages describing the possible degradation of an existing route traversing the node.

5. Decisions from the PEP to the BRuIT module regarding the processing of a flow.

- The interface between the PEP and the self-configuration layer. This interface is very simple, consisting in the information about PDPs available at the self-configuration layer. However, more complex interfaces could be designed, similar to the ad-hoc approach presented in [19].

- The COPS-extension required for the communication between the PEP and the PDP. This extension is straightforward. The COPS standard defines the possibility to encapsulate application specific requests/decision in COPS. In our case, these requests concerned the information obtained from the interface with the BRUIT module. The application specific decisions are simple install/discard decisions.

In its initial implementation, the management plane works in a full outsourcing model over the entire ad hoc network. This means that every node in charge of processing a bandwidth reservation request interacts at least once with the PDP to get a decision concerning the processing of the request (accept and propagate, deny the reservation). While this has the advantage of enabling a fine grained decision capability to the decision point, it has the disadvantage in the current BRuIT model to generate a very large message traffic overhead (namely twice the number of nodes within the network) which is unacceptable for a management overhead. This limitation can be solved through several possible changes in the decision distribution approach. One of them is to obtain the decision from the PDP only in the initiating node and then propagate the reservation request within the network together 


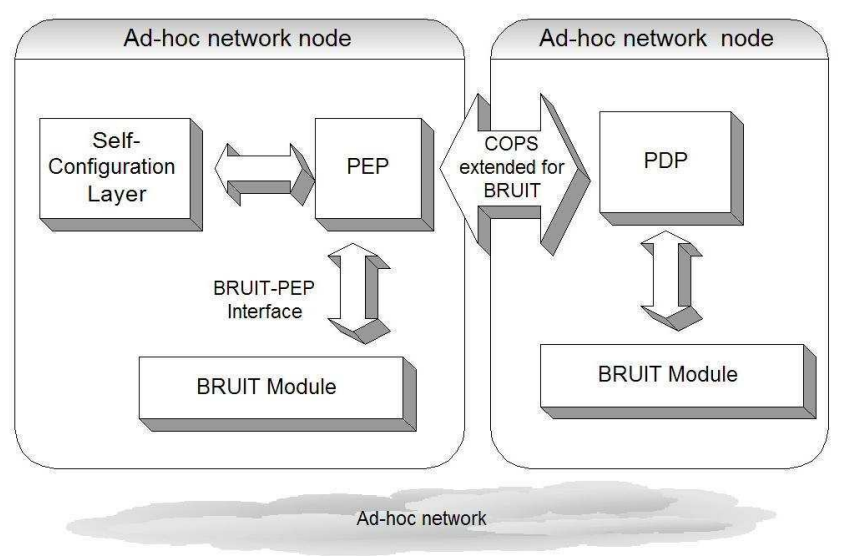

Figure 3: Ad-hoc node architecture

with its authorization. Another approach is to enter a provisioning model where policies are pushed into the devices and then decisions are taken locally. The various alternatives are currently under evaluation within the project.

\section{Conclusion}

In this paper we have presented a full bandwidth reservation framework in ad hoc networks featuring both a reservation protocol and the associated management plane.

The bandwidth reservation protocol called BRuIT, is based on extended neighborhood information to provide accurate information on the load of the radio medium. With this knowledge, the applications have better guarantees on the required bandwidth.

The management plane architecture is based on an extension of the COPS framework within an ad-hoc network. This extension is centered around two major principles. Firstly, radio level parameters are included as core building blocks of management policies. These parameters and an additional signaling support are provided by the BRuIT component. Secondly, the classical policy management framework is adapted to the case of a dynamic infrastructure. This is done by extending the simple device architecture with a self-configuration layer. This layer is responsible to dynamically bind PEPs to PDPs. A partial implementation of our architecture was developed in Java (based on the JCAPI-COPS API developed at UQAM).

As already stated in the previous section, the current implementation of the management plane, a full outsourcing model is available. In the near future, alternative models will be offered to reduce the management traffic overhead. 
Acknowledgement. Many thanks to Mrs. Hannane OUIMINA for her implementation of the COPS extension.

\section{References}

[1] Imad Aad and Claude Castelluccia. Differentiation mechanisms for IEEE 802.11. In IEEE Infocom 2001, Anchorage, Alaska, USA, April 2001.

[2] Gahng-Seop Ahn, Andrew T. Campbell, Andras Veres, and Li-Hsiang Sun. SWAN: Service differentiation in stateless wireless ad hoc networks. In IEEE INFOCOM' 2002, New York, New York, June 2002.

[3] Claude Chaudet and Isabelle Guérin Lassous. Bruit: Bandwidth reservation under interferences influence. In European Wireless 2002 (EW2002), Florence, Italy, February 2002.

[4] Shigang Chen and Klara Nahrstedt. Distributed quality-of-service routing in ad-hoc networks. IEEE Journal on Special Areas in Communications, 17(8):1-18, August 1999.

[5] W. Chen, N. Jain, and S. Singh. Anmp : Ad hoc network management protocol. IEEE Journal on Selected Areas of Communications, 17(8):1506-1531, August 1999.

[6] Verma Dinesh. Policy-Based Networking: Architecture and Algorithms. New Riders, 2000.

[7] Seoung Bum Lee, Gahng Seop Ahn, Xiaowei Zhang, and Andrew T. Campbell. Insignia: An ip-based quality of service framework for mobile ad hoc networks. Journal on Parallel and Distributed Computing, 60(4), 2000.

[8] S. Mangold, S. Choi, P. May, O. Klein, G. Hiertz, and L. Stibor. IEEE 802.11e Wireless LAN for Quality of Service (invited paper). In Proceedings of the European Wireless, volume 1, pages 32-39, Florence, Italy, February 2002.

[9] Anelise Munaretto, Hakim Badis, Khaldoun Al Agha, and Guy Pujolle. A link-state QoS routing protocol for ad hoc networks. In IEEE Conference on Mobile and Wireless Communications Networks - MWCN 2002, Stockholm, Suede, September 2002.

[10] Navid Nikaein, Christian Bonnet, Yan Moret, and Idris A. Rai. 2lqos- two-layered quality of service model for reactive routing protocols for mobile ad hoc networks. In SCI2002 - 6th World Multiconference on Systemics, Cybernetics and Informatics, Orlando, FL, United States, 2002.

[11] K. Phanse, L. DaSilva, and S Midkiff. Extending policy-based management for ad hoc networks. In Proceedings 2003 Workshop on Integrated Research and Education in Advanced Networking, Virginia, USA, April 2003.

[12] L. Romdhani, Q. Ni, and T. Turletti. AEDCF: enhanced service differentiation for ieee 802.11 wireless ad-hoc networks. Technical Report 4544, INRIA, September 2002.

[13] P. M. Ruiz, A. F. Gomez-Skarmeta, P. Martinez, J. A. Sanchez, and E. Garcia. Effective Multimedia and Multi-party Communications on multicats MANET Extensions to IP Access Networks. In Proceedings of the International Conference on Information Networking, 2003. to appear.

[14] S. H. Shah, K. Chen, and K. Nahrstedt. Dynamic Bandwidth Management in Single-hop Ad hoc Wireless Networks. In Proceeding of the IEEE Conference on Pervasive Computing and Communications, May 2003. to appea. 
[15] L Shen, C. Srisathapornphat, and C. Jaikaeo. An adaptive management architecture for ad hoc networks. IEEE Communication Magazine, 41(2):108-115, February 2003.

[16] Prasun Sinha, Raghupathy Sivakumar, and Vaduvur Bharghavan. CEDAR: a core extraction distributed ad hoc routing algorithm. IEEE Journal on Selected Areas in Communications, special issue on Wireless Ad Hoc Networks, 17(8):1454-1465, August 1999.

[17] Kui Wu and Janelle Harms. Qos support in mobile ad hoc networks. Not yet published.

[18] Hannan Xiao, Winston K.G. Seah, Anthony Lo, and Kee Chaing Chua. A flexible quality of service model for mobile ad hoc networks. In IEEE Vehicular Technology Conference, pages 445-449, Tokyo, Japan, May 2000.

[19] Nazim Agoulmine Yacine Ghamri Doudane, Anelise Munaretto. Policy control for nomadic enterprise ad hoc networks. In International Conference on Telecommunication Systems ICTS2002, Monterey, CA, USA, October 2002. 
Unité de recherche INRIA Rhône-Alpes

655, avenue de l'Europe - 38330 Montbonnot-St-Martin (France)

Unité de recherche INRIA Futurs : Domaine de Voluceau - Rocquencourt - BP 105 - 78153 Le Chesnay Cedex (France)

Unité de recherche INRIA Lorraine : LORIA, Technopôle de Nancy-Brabois - Campus scientifique 615, rue du Jardin Botanique - BP 101 - 54602 Villers-lès-Nancy Cedex (France)

Unité de recherche INRIA Rennes : IRISA, Campus universitaire de Beaulieu - 35042 Rennes Cedex (France)

Unité de recherche INRIA Rocquencourt : Domaine de Voluceau - Rocquencourt - BP 105 - 78153 Le Chesnay Cedex (France)

Unité de recherche INRIA Sophia Antipolis : 2004, route des Lucioles - BP 93 - 06902 Sophia Antipolis Cedex (France)

INRIA - Domaine de Voluceau - Rocquencourt, BP 105 - 78153 Le Chesnay Cedex (France)

http://www.inria.fr

ISSN 0249-6399 